\title{
La prevención del delito a través de prácticas situacionales
}

\section{Crime prevention through situational practices}

\author{
Fernando Luis Joao \\ Licenciado en Derecho, coronel de la Policía de Angola. Aspirante al doctorado en la Facultad de Derecho de la \\ Universidad de La Habana. \\ Correo electrónico: luisaofernando68@gmail.com
}

Rodolfo Máximo Fernández, Romo

Doctor en Ciencias Jurídicas por la Universidad de La Habana. Profesor titular de Derecho Procesal de la Facultad de Derecho de la Universidad de La Habana.

Correo electrónico:rfr6311@gmail.com

\begin{abstract}
Resumen
La prevención del delito constituye una aspiración histórica del Derecho penal y específicamente de la criminología, la que como ciencia de carácter científico y tomando como referente los estudios empíricos desarrollados regularmente, identifica en lo fundamental la prevención social comunitaria y la prevención situacional, las que con propósitos determinados se diferencian desde lo axiológico, pero presentan un objetivo común: prevenir el delito. La prevención situacional para fundamentar su contenido toma como referente las teorías de la oportunidad, la de la elección racional, la de las ventanas rotas y la del diseño ambiental, base sobre la cual se han implementado estrategias preventivas de esta naturaleza en diversos países, incluyendo países en vías de desarrollo, estimándose viable el desarrollo de estrategias de prevención situacional mediante el diseño ambiental; tiene un fundamento ideológico eminentemente pragmático y utilitarista; su objetivo no es otro que mantener en límites admisibles el delito como fenómeno social multicausal, razón por la cual más que un conjunto de teorías contra la criminalidad deben ser estimadas acciones técnicas que tributan a una disminución consciente y deliberada del crimen. Su aporte criminológico consiste en que desconoce los procesos de estigmatización que tradicionalmente ha asumido la criminología al considerar al delincuente portador de una conducta desviada, su fundamental crítica radica en que la posible ejecución de actividades delictivas no puede descansar en la condición de ser racional del comisor del delito, toda vez que la motivación del delincuente en última instancia se supedita a condicionantes sociales y económicos, los que se corresponden con fallas estructurales de las sociedades actuales, propias del neoliberalismo.
\end{abstract}

Palabras clave: Prevención situacional, actividades rutinarias, diseño ambiental, policía comunitaria, elección racional.

\begin{abstract}
The prevention of crime constitutes a historical aspiration of criminal law and specifically of criminology, which as a science of a scientific nature and taking as reference the empirical studies developed regularly, fundamentally identifies community social prevention and situational prevention, which with Certain purposes differ from the axiological, but have a common goal to prevent crime. Situational prevention to
\end{abstract}


support its content takes as a reference the theories of opportunity, rational choice, broken windows and environmental design, the basis on which preventive strategies of this nature have been implemented in various countries including countries in the process of development, the development of situational prevention strategies through environmental design being considered feasible; it has an eminently pragmatic and utilitarian ideological foundation; Its objective is simply to maintain crime as a multi-causal social phenomenon in admissible limits, which is why more than a set of theories against crime should be considered technical actions that pay a conscious and deliberate decrease in crime. Its criminological contribution is that it ignores the stigmatization processes that Criminology has traditionally assumed when considering the delinquent carrier of deviant behavior, its fundamental criticism is that the possible execution of criminal activities can not rest on the condition of being a rational commander. of crime, since the motivation of the offender is ultimately subordinated to social and economic conditions, which correspond to structural failures of current societies, typical of neoliberalism.

Keywods: Situational prevention, routine activities, environmental design, community policing, rational choice.

\section{Résumé}

La prévention de la criminalité constitue une aspiration historique du droit pénal et plus particulièrement de la criminologie, qui, en tant que science de nature scientifique et s'appuyant sur des études empiriques menées régulièrement, identifie essentiellement la prévention sociale communautaire et la prévention situationnelle, qui Certains objectifs diffèrent des objectifs axiologiques, mais présentent un objectif commun de prévention du crime. La prévention situationnelle pour fonder son contenu prend comme référence les théories de l'opportunité, celle du choix rationnel, celle des vitres brisées et celle de la conception environnementale, base sur laquelle des stratégies préventives de cette nature ont été mises en œuvre dans divers pays, y compris des pays en cours d'élaboration, compte tenu de l'élaboration de stratégies de prévention situationnelles viables au moyen d'une conception environnementale; il a un fondement idéologique éminemment pragmatique et utilitaire; Son objectif n'est autre que de maintenir la criminalité en tant que phénomène social multicausal dans les limites permises. C'est pourquoi il faudrait estimer plus qu'un ensemble de théories contre la criminalité en considérant les actions techniques contribuant à une diminution consciente et délibérée de la criminalité. Sa contribution criminologique est qu'il ne connaît pas les processus de stigmatisation que la criminologie a traditionnellement adoptés lorsqu'il considère que le délinquant a un comportement déviant. Sa critique fondamentale est que l'exécution éventuelle d'activités criminelles ne peut reposer sur la rationalité du commissaire du crime, puisque la motivation du délinquant est finalement soumise aux conditions sociales et économiques, qui correspondent aux défaillances structurelles des sociétés actuelles, typiques du néolibéralisme.

Mots-clés: Prévention de la situation, activités de routine, conception environnementale, police de proximité, choix rationnel. 


\section{La prevención del delito a través de prácticas situacionales $^{1}$}

Fernando Luis Joao

Rodolfo Máximo Fernández Romo

\section{INTRODUCCIÓN}

El aumento de la criminalidad constituye uno de los problemas que aquejan a los gobiernos en la actualidad y cómo contribuir a su prevención se encuentra incluido en sus planes de desarrollo para asegurar la gobernabilidad democrática y la armónica convivencia social; pues el delito como fenómeno que obedece a disímiles causas no solo tiene un alto impacto social, sino también representa un reto en sus costos públicos y privados.

Si en la década de los 80 del pasado siglo, las encuestas de opinión pública centraban la atención en aspectos como la pobreza, el desempleo y las guerras, a partir de los 90 las opiniones giran la mirada al tema de la criminalidad y la violencia, categorías criminológicas que ocupan primer plano en las agendas de los gobernantes, las que obedecen a múltiples factores.

A la diversa gama de delitos y formas de violencia pueden asociarse múltiples explicaciones (sociológicas, culturales, políticas, etc.) así mismo, entre sus causas se relacionan factores estructurales como la desigualdad en el ingreso, de oportunidades, cultura de guerra, valores sociales, etc. y factores de riesgo como la portación de armas, desmedido consumo de alcohol, drogas, prostitución, entre otros.

No obstante, a la reconocida incapacidad del sistema de administración de justicia penal para ofrecer respuesta viable al fenómeno criminal, parte de los ciudadanos depositan sus esperanzas en controlar y disminuir el delito a través del propio sistema penal, ya que en muchos escenarios se concibe como un fenómeno individual, desconectado de la estructura socio económica de la cual emerge y se ignoran las dinámicas estructurales que le subyacen, atacan la manifestación del problema y con ello solo ofrecen respuestas condenadas al fracaso; otros, conscientes de los riesgos y consecuencias que entraña para el ejercicio de las libertades y garantías individuales y los escasos éxitos alcanzados con la represión, optan por promover la prevención delictiva.

1 Artículo de investigación resultado de los avances de la tesis doctoral que se desarrolla en el Departamento de Ciencias Penales y Criminológicas de la Facultad de Derecho de la Universidad de La Habana. Proyecto: Cuba bajo el tema: La prevención situacional de los delitos contra el patrimonio en el municipio Viana, provincia de Luanda, República de Angola. 
Para abordar efectiva y democráticamente el tema de la actividad delictiva, se requiere diseñar y ejecutar políticas públicas que, sin abandonar lo represivo, acentúen lo preventivo, al tiempo que estimulen la participación ciudadana. Esta propuesta la desarrolla el Programa de las Naciones Unidas bajo su esquema de "seguridad ciudadana" (ONU, PNUD, 2016).

El referido informe destaca la intervención que en años recientes exhiben algunos gobiernos municipales en este campo, los que en ejercicio de sus funciones y competencias adquieren un rol destacado en la prevención del delito por varias razones: porque al estimular el desarrollo local, generan oportunidades económicas, sociales y culturales efectivas que ayudan a evitar la emergencia de ciertas manifestaciones criminales y con ello contribuyen a la prevención social del delito, porque puede evitar la comisión de ciertos delitos al mejorar la dimensión espacial del territorio, y porque está en capacidad de incentivar la participación comunitaria en un modelo que promueve, ya no solo la colaboración con los cuerpos policiales, líneas de denuncia, comités barriales de vigilancias, etc., sino más bien la inclusión política.

El panorama de inseguridad que se vive en diversos países del orbe, obliga a evaluar las distintas razones que favorecen a que la criminalidad vaya en aumento y si bien la seguridad es medida con base en percepciones, no hay día que los medios de comunicación dejen de registrar hechos delictivos y de violencia, sin que se vislumbre un plan de trabajo concreto y permanente de parte de las autoridades encargadas de la seguridad pública, sino que en lo fundamental se ofrecen soluciones operativas de represión.

Al margen de las tradicionales formas o modelos de prevención delictiva tradicional como el comunitario, desde las últimas décadas del pasado siglo se desarrolla un nuevo modelo de prevención del delito que se inspira teóricamente en las denominadas teorías del crimen y encuentran su base social en las precauciones rutinarias frente al delito, denominado prevención situacional, el que demuestra ser un instrumento eficaz para prevenir una amplia gama de acciones ilegales (Huertas, 2019). Los partidarios del modelo consideran que la prevención delictiva es una responsabilidad de todos y no solamente de las agencias de control social formal y en especial del sistema de justicia penal.

Concebir el enfrentamiento al fenómeno criminal con sentido pragmático, lleva a un diferente entendimiento de prevenir la delincuencia, ya que pone especial énfasis en las oportunidades delictivas y resultan indiferentes las condicionantes de otra índole, como pueden ser la situación económica o la salud psicológica del sujeto delincuente. Modelo de prevención que no pretende disminuir las tendencias o criminales mediante la mejora de la sociedad o sus instituciones, sino que persigue hacer el delito menos atractivo para los potenciales delincuentes, y para ello se parte de la tesis que, para prevenir en términos admisibles el delito se deben reducir las oportunidades que lo generan a través de la modificación del medioambiente en que se produce o las situaciones que lo facilitan. 
Conforme a la prevención delictiva desde lo situacional, se admite que en la medida en que los delincuentes son actores racionales estarán menos inclinados a cometer delitos si perciben que las oportunidades para su comisión son reducidas, o si perciben que los costes y riesgos asociados con la ejecución de un particular acto delictivo en un determinado lugar y momento son especialmente elevados.

A los efectos preventivos, la adopción de esquemas de prevención situacional por la policía, a través del desarrollo de la noción de policía al servicio de la comunidad, de solución de problemas, por ejemplo, supone un tránsito del modelo policial reactivo a un modelo policial proactivo en el que los policías diseñan estrategias de prevención específicas para poner fin a los problemas que provocan la concentración espacial y temporal del delito.

Hoy, toda acción preventiva desde lo situacional resulta viable y aunque algunos optan por el modelo comunitario como paradigma de prevención, se debe admitir que la combinación de ambas formas no resultan antagónicas y pueden concebirse de manera armónica a través de una estrategia integral, partiendo de que todo esfuerzo consciente y racional con vista a la prevención será válido a los efectos de salvaguardar la seguridad ciudadana, la disminución de actividades ilegales y lograr términos admisibles de paz social.

\section{DESARROLLO}

La prevención situacional es acuñada como manera de evitar el delito en el año 1976, por el británico Ronald Clarke, quien demuestra que los cambios efectuados en el servicio del gas de uso doméstico en Gran Bretaña provocaron la caída del índice de suicidios hasta entonces en aumento, lo que generó la idea de que si el control sobre determinada sustancia generaba una disminución de esta actividad, determinadas formas de control podrían ser válidas para evitar también otros actos delictivos (Clarke, 1998).

Con similares fundamentos, Ray Jeffery desarrolló en los Estados Unidos de Norteamérica en los años 70 estudios sobre la "prevención criminal a través de la modificación del ambiente físico", cuyos resultados coincidentes con los obtenidos por Clarke conformaron la "teoría de la prevención situacional del delito" (Jeffery, 1971).

Conforme a los fundamentos de la prevención situacional el diario ir y venir rutinario de cada día convierte al ciudadano común en una víctima posible y brinda oportunidades a presuntos delincuentes a la ideación, preparación y consumación de acciones delictivas. Por tanto, la solución que se ofrece es convertir al ciudadano en tan inexpugnable como se pueda y evitar así su victimización (Garrido y Redondo, 2001; Medina, 1997).

La teoría de la prevención situacional busca crear en el ambiente físico obstáculos que no permitan que el delincuente tenga éxito en su intento criminal, porque para ella el delito ocurre cuando coinciden tres factores, a saber, un agresor motivado, un 
objeto disponible y la ausencia de vigilancia; basta que uno de estos tres factores deje de existir para que el delincuente cambie su comportamiento delictivo y no cometa la acción penada por la ley.

Las más recientes teorías situacionales o de la oportunidad proponen como explicación preferente de la actividad criminal la exposición de individuos delictivamente a especiales oportunidades delictivas, ya sea de propiedades desprotegidas o de víctimas vulnerables, lo que ayuda a comprender la mayor concentración de delitos en ciertos barrios y zonas de las ciudades.

Las teorías criminológicas actuales relacionadas con la prevención situacional actúan formando descripciones elaboradas y relevantes de algunas de las interacciones más frecuentes entre dimensiones de riesgo y actos delictivos, de lo que se derivan las llamadas teorías del control, basadas en el control del barrio, vecinos, familia, empleados, así como del modo de vida o de las condiciones de la vivienda, la arquitectura del entorno, entre otros, para tornar más difícil la práctica delictiva e impedir la confluencia de los factores necesarios para el crimen antes descritos: el delincuente motivado, el objeto atractivo y la ausencia del control.

La idea de intervenir en el contexto, aunque con pequeñas modificaciones puede tener un efecto reductor sobre los fenómenos delictivos o sobre la victimización, está en la base de la prevención situacional. El marco teórico de esta estrategia preventiva se desglosa de las teorías de las oportunidades, entendiéndolas como un conjunto de varios enfoques de la "vida cotidiana" que van desde la teoría de la elección racional hasta la broken windows theory (Wilson y Kelling, 1982).

Para Ronald Clarke, en contraste con la criminología convencional, la prevención situacional representa una revolución en el ámbito criminológico, a partir del análisis que realiza de las circunstancias que dan lugar a formas específicas de delitos, al introducir discretos cambios ambientales para reducir las oportunidades de que estos ocurran (Clarke, 1997).

El ámbito de aplicación de las estrategias de prevención situacional Clarke la extiende a delitos de naturaleza no convencional por su distinto contenido de aquellos comunes, como los delitos cibernéticos, confirmando la tendencia que hace de la prevención situacional, no una de las estrategias preventivas disponibles, sino la estrategia efectiva por excelencia (Da Silva, 2017).

La prevención situacional, como forma de evitar el acto ilegal se focaliza sobre el escenario del crimen más que sobre los que cometen actos delictivos. Busca impedir la ocurrencia del delito más que detectar y sancionar a los ofensores y no busca eliminar las tendencias delictivas a través de la transformación de la sociedad, sino meramente hacer las acciones delictivas menos atractivas para los delincuentes, de ahí su carácter utilitarista y aparentemente desideologizado (Clarke, 2001).

Las estrategias vinculadas a la prevención situacional del delito se definen como las medidas dirigidas a una forma de delito sumamente específica, que implican la gestión, diseño o manipulación del ambiente inmediato de forma sistemática y 
permanente para posibilitar la reducción de las oportunidades para cometer delitos e incrementar el riesgo percibido para un amplio rango de delincuentes (Medina, 1998).

Una variante de la prevención situacional apunta a establecer estrategias preventivas a nivel local y barrial, en las que se integren las autoridades del lugar, el comercio y la ciudadanía para fomentar buenas prácticas que permitan asegurar tanto las construcciones como los espacios públicos a través de la disuasión y así evitar la existencia de blancos atractivos para la ejecución de actividades delictivas, reduciendo su riesgo por medio de la creación de factores situacionales que pueden ser capaces de manipular con este objetivo. Esta forma de prevención reconoce la estrategia de prevención del crimen a través del diseño ambiental (Crime Prevention Through Environmental Design - CPTED, por sus siglas en inglés).

A su vez, la prevención del crimen a través del diseño ambiental tiene como fundamento un conjunto de estudios que validan su metodología. Uno de estos estudios, es el que realiza Jane Jacobs conocido como "Los ojos en la calle", según el cual la seguridad en los espacios urbanos tiene directa relación con la posibilidad del contacto y creación de lazos de confianza entre las comunidades, su denominación obedece al hecho de que el diseño arquitectónico y vial que se realice debe estar orientado a facilitar la organización del medio ambiente urbano para un mejor mecanismo de vigilancia natural (Jacobs, 1965).

Otra mirada de la concepción situacional de la prevención se advierte en los estudios empíricos realizados por Oscar Newman, los que denomina "Teoría de los espacios defendibles", donde su principal propuesta estriba en la distinción que realiza entre el espacio público y el espacio privado en la construcción de espacios urbanos, en cada uno de los cuales se debe tener en cuenta exigencias que eviten la comisión de acciones ilegales (Newman, 1996).

La teoría de los espacios defendibles resulta una efectiva herramienta para el enfrentamiento de los problemas de criminalidad y vandalismo que tienen lugar en zonas de grandes construcciones habitacionales, entre los que se destacan monumentales edificios y grupos de viviendas, donde uno de los principales riesgos identificados es la imposibilidad de distinguir a los convivientes de los extraños a la comunidad, por el constante flujo de personas y la existencia de múltiples accesos que entorpecen la adecuada identificación y el regio control de entes ajenos, lo que facilita la acción de los delincuentes.

Desde lo situacional, el diseño y la ejecución de medidas para la construcción de "espacios defendibles" hacen posible aumentar la vigilancia y el control, con la correspondiente reducción del anonimato y de las vías de escapatoria de los delincuentes. La finalidad de los "espacios defendibles" es promover el rediseño físico de la arquitectura y trazado de una comunidad que permita a los residentes fiscalizar la ecología ambiental de sus hogares, incluyendo las calles, jardines y otros espacios físicos para resguardar el área (Newman, 1996; Clarke, 2001). 
En la delineación de toda estrategia de prevención situacional del delito mediante el diseño ambiental, juega un rol determinante la teoría de la decisión racional, en cuanto a que intenta estudiar el proceso de toma de decisiones de un potencial agresor y establecer medidas que permitan implementar medidas de desaliento al posible comisor y así reducir las oportunidades para realizarlo; medidas que transforman y mejoran las variables situacionales que permitan prevenir o eliminar ciertos tipos de delitos, para que el agresor perciba que el contexto en el que puede realizar su acción tiende a minimizarse o eliminarse.

La estrategia de prevención situacional del delito mediante el diseño ambiental se extiende desde dos perspectivas; una que orienta su desarrollo a la reducción del riesgo de victimización de un acto delictivo, poniendo acento en la protección del blanco, como se implementa tradicionalmente en Inglaterra, y desde otro punto de vista se hace énfasis en la modificación del entorno, con un doble objetivo que busca disminuir las posibilidades de que se pueda cometer un delito y además reducir el temor que las personas perciben en determinados espacios públicos, como criterio de seguridad ciudadana. Ambas formas se pueden tener en cuenta y pueden resultar complementarias de conformidad con las necesidades territoriales y comunitarias en correspondencia con las exigencias tradicionales de seguridad.

La prevención del delito a través del diseño ambiental tiene como fundamento una visión multidisciplinaria que busca "reducir las oportunidades de cometer delitos de oportunidad así como reducir el temor de la comunidad aumentando la cohesión comunitaria" (Hein, y Rau, 2004). Un principio elemental que la caracteriza es lograr la implicación de la comunidad en los procesos de diagnóstico, diseño, evaluación, planificación y edificación del espacio de uso común y cotidiano, a los efectos de lograr un contexto urbano más seguro.

Una estrategia de prevención del delito por medio del diseño ambiental debe buscar afrontar la localización espacial de los hechos delictivos asociada a la victimización, con especial énfasis donde las estadísticas muestran una mayor concentración de hechos, lo que genera sensación de inseguridad. Localización espacial que se identifica con la percepción de temor que refiere sentir la ciudadanía, donde aprecia una mayor vulnerabilidad e inseguridad de hacer uso de los espacios comunes por el peligro o temor que ello representa. De igual modo, la localización espacial aborda la percepción de desorden social existente, lo que remite a la ausencia de mantenimiento regular y sistemático del entorno urbano y su limpieza, así como el consumo de alcohol y drogas en lugares públicos.

Al abordar las estrategias dirigidas a la prevención del delito por medio del diseño ambiental se deben considerar cuatro componentes básicos para su implementación, entre ellos, la vigilancia natural, el refuerzo de los lazos afectivos, el control natural de accesos, y la mantención del espacio público (Hein y Rau, 2004).

El primero de ellos, la vigilancia natural, viene referido a propiciar un espacio desde donde sea posible observar y ser observado por otros en el lugar, lo que tiene como finalidad lograr la inhibición del delincuente respecto a la comisión de ilícitos, 
acrecentando la visibilidad del espacio o promoviendo su uso, y con ello el control de parte de la ciudadanía.

El refuerzo de lazos afectivos o fortalecimiento del compromiso social persigue elevar la identificación, el sentido de pertenencia y lograr mayor compromiso de los ciudadanos de la comunidad con los espacios públicos del entorno cotidiano, y para lograrlo se torna imprescindible la transformación de zonas sensibles en términos de conflictividad, promoviendo la pertinencia de su uso responsable y su regular mantenimiento, lo que favorece el control social comunitario sobre aquellos espacios recuperados que llegan a sentirse como suyos por cada miembro de la sociedad.

Controlar de forma natural los posibles accesos exige lograr la colocación de barricadas simbólicas o barreras físicas en determinados espacios identificados como vulnerables, con la deliberada intención de controlar, limitar, coartar y hasta evitar la circulación de personas ajenas a la comunidad, en este caso se hace referencia a implementar disímiles alternativas que pueden ir desde cerrar calles u otros accesos o de conjuntos habitacionales hasta la instalación de mobiliario urbano visible, como garitas, micro ventas, etc. que permitan la presencia de miembros de la comunidad y de esta forma realicen de manera espontánea y rutinaria la función de vigilantes naturales en el espacio de que se trate.

Finalmente, el mantenimiento de espacios públicos exige la ejecución regular de acciones que permitan el adecuado uso y orden de las diversas áreas de la ciudad, con la finalidad de corregir su natural desgaste o destrucción e impedir que emerja desidia, desinterés, descontento y falta de compromiso con ese espacio defendible de la comunidad, y se generé la destructiva sensación de inseguridad y de "tierra de nadie", lo que es un imponderable que compete a los gobiernos locales y que complementa la comunidad que disfruta de este haciendo su buen uso.

Las estrategias dirigidas al blanco pretenden proteger objetivos sensibles a actividades delictivas a través de un adecuado diseño ambiental, y se pueden desarrollar en cuatro direcciones, es decir, la protección del blanco, puede implicar su eliminación, modificación, endurecerlo o marcarlo; cuando se habla de eliminarlo se trata de desmantelar el blanco del espacio donde puede ser potencialmente atacado; modificarlo persigue cambiar sus particularidades para que resulte menos atractivo; endurecerlo va dirigido a resaltar sus características físicas e impregnarle mayor resistencia ante la posibilidad de un ataque, y marcarlo facilita su identificación, lo que hace más difícil su uso o comercialización en el mercado ilegal (Hein y Rau, 2004).

Las principales tendencias de aplicación de prevención del crimen a través del diseño ambiental provienen de Estados Unidos e Inglaterra, luego de unos años estas iniciativas comenzaron a replicarse en varios países, como Canadá, Australia, Sudáfrica, diversas naciones europeas y hoy ya se conciben en buena parte de América Latina.

La efectividad de la actividad preventiva en términos situacionales dependerá de la evaluación de oportunidades que en específicos contextos facilitan o promueven 
la comisión de una actividad ilegal, y para lograrlo se identifican diversas maneras de cambiar una situación con el propósito de minimizar las oportunidades de que se ejecuten actividades ilícitas (Camacho, 2018), entre las que se destacan:

1. Incrementando el esfuerzo que el delincuente debe llevar a cabo para poder cometer un delito.

2. Incrementando el riesgo que el delincuente debe enfrentar para completar un delito.

3. Reduciendo los beneficios o recompensas que el delincuente aspira obtener al completar un delito.

4. Limitando las excusas que el delincuente puede emplear para "racionalizar" o justificar sus acciones.

5. Reduciendo o evitando las provocaciones que pueden incitar o tentar a un delincuente a cometer actos criminales.

\section{CUESTIONAMIENTOS IDEOLÓGICOS A LAS ESTRATEGIAS DE PREVENCIÓN SITUACIONAL}

Las estrategias de prevención situacional al estimar al sujeto delincuente como alguien racional que elige cometer delitos, deja sentado que todos los mortales en tanto seres con capacidad de raciocinio están condicionados a la comisión de actividades ilícitas, obviando el rol de los valores morales y éticos, incorporados por la familia, la escuela y la propia sociedad en el proceso de formación de la personalidad del individuo, con el claro propósito de que sea capaz de respetar las normas de convivencia social mayormente aceptadas, lo que durante el desarrollo de la humanidad ha sido una meta de la civilización humana alcanzada por muchos.

Al proponerse prevenir situacionalmente el delito se concibe a las potenciales víctimas como responsables de sus propias desgracias, las que generan con su actuación situaciones que las victimizan, al punto de estimarla "un sujeto responsable de su condición, que no ha tenido en cuenta los recaudos necesarios para poder disuadir o prevenir la comisión del delito que lo convierte en tal"' (Schulman, 2018).

$\mathrm{Si}$ bien es cierto que existen estudios científicos que intentan cuestionarse la contribución de la víctima a la consumación delictiva, a través de la conocida victimodogmática (Rodríguez, 2012), el exacerbar el papel de la autorresponsabilidad individual respecto al control del delito, se entregan al ciudadano responsabilidades que corresponden históricamente materializar al Estado.

Conceder la importante responsabilidad de autoprotección desde lo situacional al ciudadano lo obliga a autoprocurarse su seguridad como bien público que ha de avalar todo Estado garantista, quien es conminado a obtener todo tipo de tecnología para lograrlo, desde las más básicas o elementales como rejas, muros cargados de electricidad, etc., hasta las más sofisticadas como cámaras de seguridad inteligentes, alarmas, sensores de humanos, etc., de forma que adapte el medio ambiente donde 
convive a exigencias capaces de disuadir la comisión de delitos y con ello reduzca las posibilidades de sumarse al listado de potenciales víctimas.

Detrás de la constante exacerbación al consumo de toda la parafernalia tecnológica constantemente renovada a la indefensa ciudadanía, bajo la aparente finalidad de autoprotección de probables actividades ilegales se intenta ocultar un lucrativo negocio privado, en detrimento de la economía personal de las posibles víctimas, quienes desde ese instante ya son victimizadas masivamente por la economía neoliberal hoy imperante; práctica securitizante que intenta a su vez desviar la atención de la real incapacidad de los gobiernos de ofrecer la seguridad que demanda la sociedad, de manera que el discurso neoliberal concede en lo fundamental al ciudadano la responsabilidad de seguridad y control del delito (Garland, 2008).

Así, las estrategias de prevención situacional frente a la problemática de la inseguridad ante la incapacidad de los Estados de solventar esta función, traducida entre otros aspectos en falta de voluntad política en el marco del neoliberalismo, se posiciona como el mecanismo ideal para hacer frente al delito y encargarse de su control (Schulman, 2018).

En este contexto se puede producir además un proceso de segregación urbana (Rodríguez y Arraigada, 2004) que puede observarse como una tendencia a la autoexclusión por parte de ciertos sectores de la sociedad que buscan lugares y ambientes controlados, exclusivos para un tipo de población con un estatus diferente al común de los ciudadanos, por supuesto de jugosos recursos económicos, que discrimina al obrero y al trabajador de a pie, en el que la seguridad y el control del delito se convierte en un privilegio de quienes pueden pagarla y sostenerla.

Entre las certeras críticas que desde lo ideológico se hacen a la prevención situacional se destaca la crítica de Muñoz Conde, quien argumenta que la prevención situacional es apenas una forma elemental de prevenir a la delincuencia donde el Estado transfiere al ciudadano responsabilidades que son suyas.

Juzga, inadmisible como forma de prevención de la delincuencia que sea recomendable a las personas que no transporten dinero, que cierren bien las puertas de las casas, que pongan alarmas en los coches y casas "y que asuman las consecuencias que inevitablemente se producirán si no se adoptan este tipo de precauciones situacionales" (Muñoz, 2001).

Refuta también, que el límite de garantías de los derechos fundamentales es muy bajo y que la falta de prevención eficaz desarrollada por los organismos oficiales lleva a tener como consecuencia una sociedad de convivencia no armónica y libremente organizada.

\section{CUESTIONAMIENTOS TÉCNICOS JURÍDICOS A LAS ESTRATEGIAS DE PREVENCIÓN SITUACIONAL}

Ferrajoli (1997) estima la prevención situacional como alternativa al Derecho Penal y en tanto la concibe como parte de lo que se llama sistema de "control estatal- 
disciplinario", donde el Estado como forma de prevenir a la delincuencia hace uso de medios de control total del ciudadano, consistentes en "un peligro futuro" con uso de control informático, audiovisual y de fichamiento generalizado, con rígidas reglas de autoreglamentación y persecuciones (Ferrajoli, 1997).

Para Larrauri Pijoan y Cid Moliné algunas de las medidas de prevención situacional tienen carácter de penas con fines de incapacitar al delincuente, tal es el caso de la retirada del carné de conducir para el culpable de manejar bajo la influencia de alcohol (Cid Moliné y Larrauri, 2014).

\section{CUESTIONAMIENTOS PRÁCTICOS A LAS ESTRATEGIAS DE PREVENCIÓN SITUACIONAL}

Doctrinalmente la crítica sostiene que, en vez de reducir el delito, la prevención situacional hace que este se desplace a otra zona, que el delincuente cambie los objetos del delito o cambie para una u otra forma delictiva menos grave, lo que es conocido como desplazamiento benigno y se traduce, por ejemplo, en el cambio de armas de fuego por armas blancas, que es menos letal y requiere más fuerza y agilidad del delincuente (Medina, 1998; Soto, 2003; Cerezo y Díez, 2010).

En tal sentido Diego Torrente considera que estos desplazamientos pueden ser de naturaleza temporal, que es cuando "los delitos se cometen en diferentes momentos o se aplazan temporalmente" (Torrente, 2001); espaciales cuando hay cambio de barrio; tácticos cuando cambian los métodos de practicar el delito; desplazamiento del objetivo cuando el delito puede ser desviado de un objetivo hacia otro o funcionales cuando cambia una forma delictiva por otra. Felson y Clarke señalan el concepto de desplazamiento del objetivo visto cuando el objetivo del crimen cambia para otro.

Con respecto a este desplazamiento es trascendental definir las condiciones de ocurrencia:

a. Si los actores motivacionales que influyen al delincuente son muy fuertes.

b. Si existen muchos objetivos alternativos que son disponibles o son percibidos como tales.

c. Si quienes diseñan los programas de prevención no consideran en sus planes de intervención las formas más evidentes de desplazamiento y diseñan contramedidas para atajarlas.

d. Si existen objetivos vulnerables cerca de los objetivos que se están protegiendo.

La edad del delincuente también influye en el desplazamiento, el delincuente joven no se desplaza para una localidad muy distante de la habitual o para la práctica de delitos con un mayor grado de sofisticación. La familiaridad del delincuente con el ambiente del delito también es importante porque prefiere "trabajar" en zonas conocidas que cambiar para otras desconocidas. 
Además, los costes del desplazamiento para el delincuente tendrían que superar los beneficios. Lo que refuerza la conclusión de que el desplazamiento ocurre con menos frecuencia o de manera menos completa de lo que se pensaba en un principio.

Las críticas sobre el desplazamiento no tienen la misma importancia que aquellas que hablan de las garantías del ciudadano frente a un Estado cada vez más invasor y controlador, pero sí es cardinal considerar la importancia que han tenido hasta ahora algunas de las muchas técnicas de prevención situacional en el control del delito, lo que concede a esta teoría una importancia que no se puede rechazar si se considera el abanico de crímenes que pueden ser prevenidos con el uso de ellas.

Otro punto llamado a crítica es que el ciudadano hoy es transparente no solamente para los órganos de control oficial sino también para los informales, como son, los porteros de los edificios de residencias, centros laborales y de las escuelas, porque no hay sector de la vida que no quede bajo alguna forma de control, lo que hace casi imposible hablar del derecho de la privacidad o intimidad cuando el hombre se encuentra cercado por instrumentos de prevención, sea de la criminalidad e incluso prevención de naturaleza política. Así, hoy son cada vez más frecuentes las violaciones a la privacidad de las comunicaciones, al ser cada día más fácil poner bajo escucha las comunicaciones por teléfono de cualquier individuo con la justificativa de que tal control se destina a investigar la ocurrencia de delitos.

Hay que recordar que "la violencia" es, desde luego un problema social, pero también un problema semántico, porque solo a partir de un determinado contexto social, político o económico pueda ser valorada, explicada o defendida. No se puede concebir un concepto de violencia estático o ahistórico, que pueda darse al margen del contexto social en el que surge (Muñoz, 1985).

\section{EFICACIA DE LA PREVENCIÓN SITUACIONAL}

Para medir eficacia cabe preguntarse ¿previene el delito la prevención situacional? La respuesta parte de la prevención misma. La prevención del delito es un tema complejo, que al igual que una ecuación matemática presenta muchas variables que se transforman conforme cambian las circunstancias a su alrededor, por lo que se debe tener claro que es una experiencia que requiere exploración constante, estudio y un pensamiento capaz de cambiar conforme cambie la ecuación.

Lo ideal de prevenir mediante la situacionalidad es que ubica en tiempo, espacio, ocurrencia y circunstancia al delito, no suscribe a una idea estrecha, brinda elementos para innovar a partir de las debilidades propias, porque es la persona la máxima responsable de su seguridad, de tal suerte, un fallo en su aplicación no es más que un fallo en sí mismo, que obliga a instruirse en el arte de cuidarse realmente bien.

Con la prevención situacional se elimina la sucesión del delincuente motivado que encuentra a la víctima perfecta y el objeto deseado sin vigilancia, "incrementando el esfuerzo necesario para cometer un delito, minimizando las recompensas del delito y aumentando las probabilidades de ser detectado" (Torrente, 2001). 
De manera que su éxito radica en hacer casi imposible el triunfo de la conducta delincuencial, a partir de la modificación del ambiente que entraña que esta práctica sea bien difícil o muy arriesgada y con ello se reduzca el éxito de la conducta delictiva, lo que no se hace atrayente por el esfuerzo demasiado elevado que demanda. Si se dificulta la vía al objeto, se opta por una manera eficaz de reducir el delito.

\section{CONCLUSIONES}

La prevención del delito constituye una aspiración histórica del derecho penal y específicamente de la criminología, la que como ciencia de carácter científico y tomando como referente los estudios empíricos desarrollados regularmente, identifica en lo fundamental la prevención social comunitaria y la prevención situacional, las que con propósitos determinados se diferencian desde lo ideológico y axiológico, pero presentan como objetivo común prevenir el delito.

La prevención situacional tiene un fundamento ideológico eminentemente pragmático y utilitarista, su propósito político criminal no está encaminado al mejoramiento humano del delincuente, ni tampoco tiene como finalidad eliminar los males que aquejan a las sociedades actuales; su objetivo no es otro que mantener en límites admisibles el delito como fenómeno social de diversa índole, razón por la cual más que un conjunto de teorías contra la criminalidad deben ser estimadas acciones técnicas que tributan a una disminución consciente y deliberada del crimen.

La prevención situacional identifica una problemática de índole ético-moral, ya que su aplicación puede suponer un recorte de las libertades y derechos individuales que debe considerarse y controlarse, primando, en todo caso, su efectividad en la reducción de la delincuencia y sobre todo la consideración de derechos individuales o colectivos en juego.

El aporte criminológico de la prevención del delito desde lo situacional consiste en que deja a un lado los procesos de estigmatización que tradicionalmente ha asumido la criminología que atribuye al delincuente ser portador de una conducta desviada. La fundamental crítica que puede recibir esta técnica de prevención delictiva radica en que la posible ejecución de actividades delictivas no puede descansar en la condición de ser racional del comisor del delito, toda vez que la motivación del agresor en los delitos comunes, como por ejemplo contra el patrimonio, se supedita en última instancia a condicionantes sociales y económicas, las que se corresponden con fallas estructurales de las sociedades actuales, propias del neoliberalismo.

Como técnica de prevención del crimen, se le identifican otras limitaciones; la primera, que puede utilizarse básicamente para evitar delitos racionales, lo que lejos de considerarse un problema, permite una valoración positiva de la técnica, puesto que la mayoría de los delitos que se perpetran son delitos contra la propiedad u otros similares en los que pocas veces entra en juego el componente emocional. Tampoco el problema del desplazamiento territorial del delito debe ser asumido como limitante, ya que si bien el desplazamiento es real, los efectos del delito se minimizan respecto 
de los que se hubiesen producido en el lugar original. No obstante, se visualiza como un más para enfrentar la delincuencia en el contexto social actual.

\section{REFERENCIAS}

Camacho, J. (s.f.). La prevención del delito situacional. Grupo Mundial de Policías. Recuperado el 12 de julio de 2018, de www.popcenter.org/library/pdfs/espanol/ scp_esp.pdf.

Cid Moliné, J., y Larrauri, E. (2014). Teorías criminológicas explicación prevención delincuencia. Editorial Bosch.

Clarke, R. V. (1995). Situational crime prevention. Guilderland, New Your: Harrow and Heston.

Clarke, R. V. (1997). Situational Crime Prevention: Successful Case Studies. (2a ed.). Albany, New York: Harrow and Heston.

Clarke, R. V. (2001). Crime Prevention through Environmental Design. Paper presented on EU conference in Sündsvall, Sweden.

Da Silva, W. P. (2017, octubre). Fundamentos criminológicos y jurídicos de la previsión legal de los delitos informáticos. Tesis de doctor en Ciencias Jurídicas, Universidad de La Habana, Facultad de Derecho, Departamento Ciencias Penales y Criminológica. La Habana, Cuba.

Felson, M. y Clarke, R. V. (1998). Opportunity makes the thief. Practical theory for crime prevention. Police Research Series, Home Office. London. Research, Development and Statistics Directorate.

Ferrajoli, L. (1997). Derecho y razón. Teoría del Garantismo Penal. Madrid, España: Editorial Trotta, S.A.

Garland, D. (2005). La cultura del control. Buenos Aires: Editorial Gedisa.

Garrido, V., y Redondo, S. (2001). Principios de criminología. (2a. ed.). Valencia: Tirant lo Blanch.

Hein, A. y Rau, M. (2004). Estudio comparado de políticas de prevención del crimen mediante el diseño ambiental CPTED. Fundación Paz Ciudadana. Home Office. Santiago.

Huertas, O. (2019). Principio de legalidad penal y justicia transicional en Colombia - Legalidad estricta o legalidad flexible. Bogotá: Grupo Editorial Ibáñez.

Jacobs, J. (1965). The Death and Life of Great American Cities. Londres, Harmondsworth: Penguin.

Jeffery, C. R. (1971). Crime Prevention Through Environmental Design. Beverly Hills, CA: Sage.

Medina, J. J. (1997). El control social del delito a través de la prevención situacional. En Cuadernos de Derecho Penal y Criminología, 15, 271-328.

Muñoz, F. (1985). Derecho penal y control social. Jerez: Fundación Universitaria de Jerez. 
Muñoz, F. (2001). Introducción a la criminología. Valencia: Editorial Tirant lo Blanch.

Newman, O. (1996). Creating Defensible Space. U.S. Department of Housing and Urban Development, Office of Policy Development and Research. Washington, D.C.

Rau, M. (2005). Prevención del crimen mediante el diseño ambiental en Latinoamérica. Un llamado a la acción ambiental comunitaria. En Dammert, L. y Paulsen, G. (Ed.). Ciudad y Seguridad en América Latina. Red14 URBAL, municipalidad de Valparaíso, FLACSO-Chile.

Rodríguez, J. y Arraigada, C. (2004, mayo). Segregación residencial en la ciudad latinoamericana. Revista Eure, XXIX(89). Santiago de Chile.

Rodríguez, L. (2012). Derecho victimal y victimodogmática. Cuaderno del Instituto Vasco de Criminología, 26.

Sabatini, F., Cáceres, G. y Cerda, J. (2001, diciembre). Segregación residencial en las principales ciudades chilenas: Tendencias de las tres últimas décadas y posibles cursos de acción. Revista Eure, XXXVII(82). Santiago de Chile.

Schulman, D. (2012, enero). Dilemas políticos de la Estrategia de prevención situacional - ambiental del delito. Criminología y Justicia. Recuperado el 12 de agosto de 2018, de http://cj-worldnews.com/spain.

Soto, C. (2013). La medición del desplazamiento y la difusión de beneficios: Aplicación del método Bowers y Johnson (2003) a la investigación de Cerezo y Díez Ripollés (2010). Revista Española de Investigación Criminológica, № .11 , artículo 2.

Sozzo, M. (2008). Inseguridad, prevención, policía. FLACSO. Quito.

Torrente, D. (2001). Desviación y delito (p. 225). Madrid: Alianza Editorial.

Torres, M. A. (s.f.). La prevención situacional del delito y las modalidades de segregación residencial. Recuperado el 22 de agosto de 2018, de http://www. ambito-juridico.com.br/site/index.php?n_link=revista_artigos_leitura\&artigo_ $\mathrm{id}=450$.

Otros documentos

ONU. PNUD. Recuperado el 23 de agosto de 2018, de https://www.undp.org/content/ dam/rblac/img/.../IDH-AL\%20Informe\%20completo.pd. 